\title{
Altered expression and molecular abnormalities of cell-cycle-regulatory proteins in rhabdomyosarcoma
}

\author{
Yukiko Takahashi ${ }^{1}$, Yoshinao Oda ${ }^{1}$, Ken-ichi Kawaguchi ${ }^{1}$, Sadafumi Tamiya ${ }^{1}$, \\ Hidetaka Yamamoto $^{1}$, Sachiyo Suita ${ }^{2}$ and Masazumi Tsuneyoshi ${ }^{1}$ \\ ${ }^{1}$ Department of Anatomic Pathology and ${ }^{2}$ Department of Pediatric Surgery, Graduate School of Medical \\ Sciences, Kyushu University, Fukuoka, Japan
}

\begin{abstract}
Rhabdomyosarcoma is the most commonly occurring soft-tissue sarcoma in children. Some reports have discussed the altered expression and molecular abnormalities of cell-cycle-regulatory proteins in rhabdomyosarcoma; however, variable frequencies of occurrence have been noted. In the current study, among 72 cases of rhabdomyosarcoma, the authors evaluated for the expression of p53, MDM2, p16, p21/WAF1, p27, cyclin D1, cyclin E, pRb and E2F-1 protein immunohistochemically and assessed for proliferative activities using MIB-1. We also analyzed the mutation of the p53 gene in 45 cases, the amplification of the MDM2 gene in 18 cases and the mutation of the $\boldsymbol{H}$-ras gene in 29 cases, using formalin-fixed paraffin-embedded materials. Furthermore, we assessed the correlation between clinicopathologic factors and the results of both immunohistochemical and molecular analyses. Alveolar type affected older patients, and it had a significantly higher mitotic rate compared with the embryonal type $(P=0.0226)$. p53 overexpression was detected in $22(30.6 \%)$ of 72 cases, and $10(22.2 \%)$ of 45 cases had p53 gene abnormalities. As for MDM2, its overexpression was found in nine (12.5\%) of 72 cases, and three $(16.7 \%)$ of 18 cases showed MDM2 amplification. A statistically significant association was observed between immunoreaction for MDM2 and p53 overexpression $(P=0.0002)$, and p53 and MDM2 overexpression was significantly correlated with high MIB-1 labeling indices. E2F-1 labeling indices showed a significantly higher score in alveolar type compared with that seen in embryonal type $(P=0.0334)$, but MIB-1 did not. In conclusion, our study suggests that p53 overexpression may be related to tumor progression because tumors with p53 overexpression have a high proliferative activity in the current study. Alveolar type had a significantly higher both mitotic rate and E2F-1 labeling indices when compared with the embryonal type. The current study is the first report of the correlation of E2F-1 with alveolar rhabdomyosarcoma.
\end{abstract}

Modern Pathology (2004) 17, 660-669, advance online publication, 16 April 2004; doi:10.1038/modpathol.3800101

Keywords: rhabdomyosarcoma; children; cell-cycle-regulatory proteins

Rhabdomyosarcoma is the most commonly occurring soft-tissue sarcoma in children. ${ }^{1}$ Based on histopathologic features, rhabdomyosarcomas can be categorized into the following types: embryonal, alveolar and pleomorphic subtypes. ${ }^{2}$ It has been reported that both the biological behavior and the clinical behavior are different depending on the above subtypes of rhabdomyosarcoma, and even within the same subtype, differences with regard to malignant behavior have been noted. ${ }^{3}$

Correspondence: Dr Y Oda, MD, Department of Anatomic Pathology, Pathological Sciences, Graduate School of Medical Sciences, Kyushu University, 3-1-1 Maidashi, Higashi-ku, Fukuoka 812-8582, Japan.

E-mail: oda@surgpath.med.kyushu-u.ac.jp

Received 8 October 2003; revised and accepted 20 January 2004; published online 16 April 2004
There have been several reports concerning the altered expression and the molecular abnormalities of the cell-cycle-regulatory proteins in rhabdomyosarcoma, as has also been reported for other softtissue tumors, and as a result, variable frequencies of occurrence have been noted. ${ }^{4-16}$ Altered cell-cycle regulation may underlie the development and/or progression of human malignancies. Many of the tumor-suppressor genes and oncogenes directly participate in or regulate the signal transduction pathways. The genes and their proteins, acting at the G1-S checkpoint, represent one of the more frequent targets in molecular tumorigenesis.

Mutation of the p53 gene is the most common alteration found in human malignant tumors and the alterations of $p 53$ have been suggested as playing a role in tumor progression. ${ }^{4,6,8,17}$ The $M D M 2$ gene products bind to p53 protein, forming a complex 
that can inhibit the p53 growth-suppressive function by blocking the transactivation domain of p53. ${ }^{18,19}$ On the other hand, the coexpression of p53 and MDM2 protein has been demonstrated as being an adverse prognostic factor in several types of soft-tissue sarcomas. ${ }^{8,20,21}$

Although several kinds of sarcoma have been analyzed, there have been few investigations utilizing a series of childhood malignant solid tumors, including rhabdomyosarcoma, especially where the focus has been on clinical specimens. ${ }^{4,5,7,10,12,14-16}$ The number of samples studied has been very small so far, and the data concerning the occurrence of disturbance in the cell-cycle-regulatory proteins involving the p53 and the $\mathrm{Rb}$ pathway have been limited, with great variations in data, such as the rate of p53 mutations ranging from 0 to $45 \% .{ }^{4-8,17}$ Furthermore, there has not been enough evaluation of the correlation between the alterations of these proteins and the clinicopathological findings in rhabdomyosarcoma. ${ }^{22}$

In addition, the ras gene family has been reported to be associated with human neoplasms, and frequent ras mutations have been reported in a number of human cancers. As for sarcomas, $H$-ras codon 12 mutations have been reported in rhabdomyosarcoma and in malignant fibrous histiocytoma. $^{23}$

The aim of this study was to define the frequency of altered expression and molecular abnormalities of cell-cycle regulatory proteins involving the p53 and the $\mathrm{Rb}$ pathway in a rather large series of rhabdomyosarcoma using clinical specimens, and to investigate their possible association with clinicopathologic features and proliferative activities.

\section{Materials and methods}

\section{Case Materials}

In all, 72 formalin-fixed, paraffin-embedded rhabdomyosarcoma specimens registerated in the Department of Anatomic Pathology between 1970 and 2001 were available for immunohistochemical studies. The diagnosis of all cases was based on light microscopic examination with hematoxylin-eosin (HE) staining according to the WHO classification in $2002^{2}$ and, where necessary, immunoperoxidase procedures using the streptavidin-biotin peroxidase (SAB) method were carried out. All the samples were from different patients, and among them nine cases had already been treated by chemotherapy or radiotherapy. Survival data were available for 64 cases. Follow-up ranged from 1 to 257 months (mean, 46.0 months). On the other hand, from among these 72 cases, 45 cases, in which the DNA was of good quality, were used for further molecular analyses.

We assessed the correlation between clinicopathologic factors (sex, age, anatomical site, histologic subtype and mitotic rate) and the results of both immunohistochemical and molecular analysis. The mitotic count was also estimated by counting mitotic figures in 10 high-power fields (HPFs).

\section{Immunohistochemistry}

The expression of cell-cycle-related proteins was investigated by immunohistochemical studies. The primary antibodies used in this study are summarized in Table 1. Histologic sections $(4-\mu \mathrm{m})$ of $10 \%$ formalin-fixed, paraffin-embedded materials were cut, mounted on glass slides coated by 3 -aminopropyltriethoxysilane and then air-dried overnight at room temperature. The sections were deparaffinized in xylene and rehydrated in ethanol, and endogenous peroxidase was blocked by methanol containing $3 \%$ hydrogen peroxidase for $15 \mathrm{~min}$. For staining with the above antibodies, sections were pretreated with citrate buffer $(0.01 \mathrm{~mol} / \mathrm{l}$ citric acid: $\mathrm{pH}$ 6.0) four times, each for $5 \mathrm{~min}$ at $100^{\circ} \mathrm{C}$ in a microwave oven. The sections were incubated with primary antibodies at $4{ }^{\circ} \mathrm{C}$ overnight, followed by staining with a streptavidin-biotin peroxidase kit (Nichirei, Tokyo, Japan). The sections were then finally reacted in a $3,3^{\prime}$-diaminobenzidine, peroxytrichloride substrate solution and counterstained with methyl green.

In the cases of p53 and MDM2, staining of more than $10 \%$ of the nuclei was needed for positive cases. In the cases of $\mathrm{p} 16$ and $\mathrm{Rb}$, the immunoreactivities were classified into three categories, defined as follows: minus sign, $0 \%$ of the nuclei were reactive; heterogeneous staining, $1-49 \%$ of the nuclei were reactive; and plus sign, more than $50 \%$ of the nuclei were reactive. Samples showing either minus or heterogeneous staining were considered abnormal. The p21, p27, cyclin D1, cyclin E, MIB-1 and E2F-1 labeling indices (LI) were determined by counting the positively stained nuclei in at least 500 tumor cells. The scoring was performed by a single

Table 1 Monoclonal antibodies used in the study

\begin{tabular}{|c|c|c|}
\hline Antigen & Dilution & Source \\
\hline Ki-67 & $1: 100$ & Immunotech, Marseille, France \\
\hline p53 & $1: 100$ & Oncogene Science, New York, NY, USA \\
\hline MDM2 & $1: 40$ & $\begin{array}{l}\text { Oncogene Research Products, } \\
\text { Cambridge, MA, USA }\end{array}$ \\
\hline p21/WAF1 & $1: 100$ & Oncogene Research Products \\
\hline $\mathrm{p} 27$ & $1: 40$ & $\begin{array}{l}\text { Novocastra Laboratories, Newcastle } \\
\text { upon Tyne, UK, UK }\end{array}$ \\
\hline p16 & $1: 50$ & Santa Cruz, CA, USA \\
\hline cyclin D1 & $1: 25$ & Novocastra Laboratories \\
\hline cyclin E & $1: 100$ & Calbiochem, Cambridge, MA, USA \\
\hline $\mathrm{pRb}$ & $1: 800$ & $\begin{array}{l}\text { Pharmingen Laboratories, San Diego, } \\
\text { CA, USA }\end{array}$ \\
\hline $\mathrm{E} 2 \mathrm{~F}-1$ & $1: 100$ & Santa Cruz, CA, USA \\
\hline
\end{tabular}


pathologist who had no prior knowledge of the clinical characteristics.

\section{Polymerase Chain Reaction-Single-Strand Conformation Polymorphism (PCR-SSCP) and DNA Sequencing for $p 53$}

Genomic $D N A$ was purified from paraffin-embedded tissues of 45 rhabdomyosarcomas, using standard proteinase $\mathrm{K}$ digestion and phenol/chloroform extraction.

The Polymerase Chain Reaction-Single-Strand Conformation Polymorphism (PCR-SSCP) method in this study was used as the method of Oda et al. ${ }^{24}$ Mutations of the p53 gene were examined from exons 5-9. After the purification of aberrantly migrating bands of p53 in the SSCP gel, direct sequencing was carried out by the dideoxy chain termination methods using a Perkin Elmer ABI Prism 310 sequence analyzer (Applied Biosystems, Foster City, CA, USA). The primers used for direct sequences were the sense and antisense primers used for PCR-SSCP in $p 53$.

\section{Differential PCR for MDM2}

The differential PCR method used to detect the amplification of MDM2 in this study was a modification of the method of Reid et al. ${ }^{24,25}$ As for a positive control, DNA of the SA-1 cell line (American Type Cell Collection, Rockville, MD, USA), which is known to show seven-fold amplification of the MDM2 gene by the radio-labeled differential PCR method, was used. After amplification, $15 \mu \mathrm{l}$ of each reaction was analyzed by electrophoresis on a $3 \%$ agarose gel, stained with ethidium bromide, and the intensities of the DNA products were quantified using a National Institutes of Health (NIH) Image Ver 1.56. The level of MDM2 amplification was determined by comparing the ratio of the intensities of the MDM2 and PAH PCR products for each of the samples with positive SA-1 cells (seven-fold). Samples showing more than two-fold amplification were judged as positive. ${ }^{9}$

\section{Polymerase Chain Reaction-Restriction Fragment Length Polymorphism (PCR-RFLP) for H-ras}

We used the PCR-RFLP procedure to detect $H$-ras mutations at codons 12 and 13 with strategy primers as reported. ${ }^{26}$ Codon 12 mutations were detected thanks to a naturally occurring HpaII site (CCGG) that is lost when the mutation occurs. HpaII digests the 71-bp-amplified fragment into two fragments (41- and 30-bp), thus revealing the presence of the normal allele, while the mutant allele remains within the undigested 71-bp fragment. This method allows the detection of a mutation of the second and third positions of codon 11 and the first and second positions of codon 12. To detect codon 13 mutation, nested primers were used to create a new restriction site for HphI (GGTGA) by changing a T for an A in the second position of codon 14, thereby allowing the detection of any mutation of codon 13 of the $\mathrm{H}$ ras gene. HphI digests the same 71-bp-amplified fragment into two fragments (58- and 13-bp), thus revealing the presence of the normal allele, while the mutant allele remains within the undigested 71bp fragment. The DNA bands were analyzed by $3 \%$ agarose gel electrophoresis, stained with ethidium bromide and then photographed.

\section{Statistical Analysis}

Fisher's exact test was used to evaluate the association between two dichotomous variables for p53, MDM2, p16 and pRb. The clinicopathologic parameters investigated in this study were classified as follows: age $(<10 \mathrm{vs} \geq 10)$, location (orbital or genitourinary (restricted nonbladder/prostate) vs others), mitotic rate ( $<15 / 10 \mathrm{HPFs}$ vs $\geq 15 / 10 \mathrm{HPFs}$ ) and histological subtype (embryonal vs alveolar). As regards the histological subtypes of this tumor, two cases with pleomorphic type were excluded from the statistical analysis because the number of samples was too small to analyze. The difference in the labeling indices of p21, p27, cyclin D1, cyclin E, MIB-1 and E2F-1 between the two groups was estimated by the Mann-Whitney test. A $P$ value of less than 0.05 was considered statistically significant.

\section{Results}

Clinicopathologic data for the patients with rhabdomyosarcoma are summarized in Table 2 . There were 41 male and 31 female patients, ranging in age from 15 days to 38 years (mean, 11.9 years). Histologically, 36 tumors were categorized as embryonal type (Figure 1), of which two as botryoid type, four as spindle cell type and one as anaplastic type. In all, 34 tumors were categorized as alveolar type (Figure 2) and two as pleomorphic type. Alveolar type (mean age, 15.8 years) occurred in older individuals than embryonal type (mean age, 8.2 years). Although rhabdomyosarcomas occurred at various sites, the most common site was the head and neck (23 cases), followed by the genitourinary area (17 cases), the extremities (12 cases), the trunk (12 cases), the retroperitoneum (three cases), the peritoneum (two cases), the pelvis (two cases), and the lung (one case). Embryonal type frequently occurred in the genitourinary area $(13 / 36 ; 36.1 \%)$, whereas alveolar type frequently occurred at the extremities (10/34; $29.4 \%$ ). As for two cases of pleomorphic type, one 10 -year-old female having a tumor in the oral cavity died of the disease 14 months after surgery, and another 16-year-old female having a tumor in the chest wall also died of the disease 7 months after 
Table 2 Clinicopathological data for rhabdomyosarcoma

\begin{tabular}{|c|c|c|c|c|}
\hline & Embryonal & Alveolar & Pleomorphic & All types of RMS \\
\hline Number & $36(50.0 \%)$ & $34(47.2 \%)$ & $2(2.8 \%)$ & 72 \\
\hline Sex (m:f) & $22: 14$ & 19:15 & $0: 2$ & $41: 31$ \\
\hline Ratio & $1.6: 1.0$ & $1.3: 1.0$ & & $1.3: 1.0$ \\
\hline Age (mean) & 8.1 years & 15.2 years & 13.0 years & 11.9 years \\
\hline Range; median & 15 day-38 years; 4 years & 2 mo-36 years; 15 years & 10 years-16 years; 13 years & 15 day-13 years; 10 years \\
\hline \multicolumn{5}{|l|}{ Location (no.) } \\
\hline Head/neck & 10 & 12 & 1 & 23 \\
\hline Parameningeal area & 1 & 0 & 0 & 1 \\
\hline Orbit & 2 & 2 & 0 & 4 \\
\hline Extremities & 2 & 10 & 0 & 12 \\
\hline Genitourinary area & 13 & 4 & 0 & 17 \\
\hline Bladder, prostate & 8 & 0 & 0 & 8 \\
\hline Other & 11 & 8 & 1 & 20 \\
\hline \multicolumn{5}{|l|}{ Mitotic rate (no.) } \\
\hline$\geq 15$ & 32 & 22 & 1 & 55 \\
\hline$\geq 15$ & 4 & 12 & 1 & 17 \\
\hline \multicolumn{5}{|l|}{ Follow-up (no.) } \\
\hline DOD & 17 & 21 & 2 & 40 \\
\hline AWD & 17 & 7 & 0 & 24 \\
\hline
\end{tabular}

$\mathrm{mo}=$ month

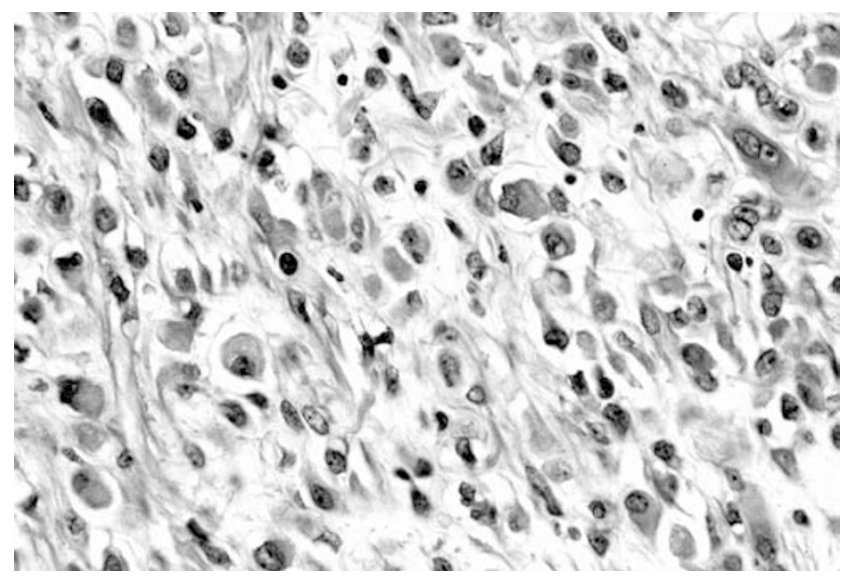

Figure 1 Embryonal type. The rounded tumor cells have hyperchromatic nuclei and some reveal an eosinophilic cytoplasm.

surgery. The mitotic rate ranged from 0 to 83 per 10 HPFs (mean, 10.3 per 10 HPFs). A total of 52 tumors $(72.2 \%)$ had less than nine mitoses per $10 \mathrm{HPFs}$, whereas $11(15.3 \%)$ had between 10 and 19 mitoses per $10 \mathrm{HPFs}$. Nine tumors (12.5\%) had more than 20 mitoses per $10 \mathrm{HPFs}$, of which seven cases were alveolar type. The mitotic rate was recorded as being high in 17 cases $(23.6 \%)$, including one case of pleomorphic type, with more than 15 mitoses per 10 HPFs. The alveolar type had significantly more numerous mitoses compared with the embryonal type (mean value for alveolar type, 16.1; mean value for embryonal type, $4.5 ; P=0.0226$ ).

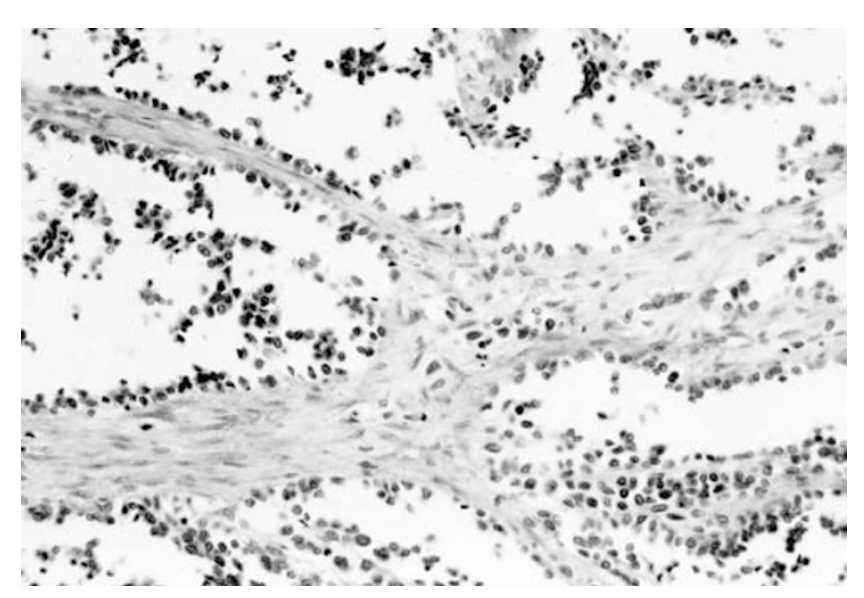

Figure 2 Alveolar type. The tumor is composed of a proliferation of rounded cells with thick collagenous septa.

\section{Immunoreactivity for All Cell-cycle-regulatory Proteins}

The results of immunohistochemical analysis are summarized in Table 3. PRb immunoreactivity showed normal expression in 19 samples (26.4\%) (Figure 3a), while altered patterns were observed in 53 samples (73.6\%) (Figure 3b). Altered staining patterns included heterogeneous expression with some cells (1-49\%) positive and others negative within the same samples. As for p16, 24 (33.3\%) samples were considered normal, while 48 (66.6\%) demonstrated altered patterns, either heterogeneous 
Table 3 Immunohistochemical analysis of histological types of rhabdomyosarcoma

\begin{tabular}{|c|c|c|c|c|}
\hline & $\begin{array}{c}\text { Embryonal } \\
(\mathrm{n}=36)\end{array}$ & $\begin{array}{l}\text { Alveolar } \\
(\mathrm{n}=34)\end{array}$ & $\begin{array}{c}\text { Pleomorphic } \\
(\mathrm{n}=2)\end{array}$ & $\begin{array}{l}\text { Overall } \\
(\mathrm{n}=72)\end{array}$ \\
\hline p53+ & $14(38.8 \%)$ & $7(20.6 \%)$ & $1(50.0 \%)$ & $22(30.6 \%)$ \\
\hline MDM2+ & $7(19.4 \%)$ & $2(5.8 \%)$ & $0(0 \%)$ & $9(12.5 \%)$ \\
\hline p16+ & $21(58.3 \%)$ & $26(76.5 \%)$ & $1(50.0 \%)$ & $48(66.7 \%)$ \\
\hline $\mathrm{RB}+$ & $30(83.3 \%)$ & $22(64.7 \%)$ & $1(50.0 \%)$ & $53(73.6 \%)$ \\
\hline *p21-LI (range) & $7.5(0-68.0)$ & $3.7(0-20.0)$ & $4.5(2.0-7.0)$ & $5.6(0-68.0)$ \\
\hline *p27-LI (range) & $5.6(0-48.0)$ & $5.6(0-64.0)$ & $2.0(0-4.0)$ & $5.5(0-64.0)$ \\
\hline *cyclin D1-LI (range) & $4.7(0-40.0)$ & $4.9(0-40.0)$ & $0.5(0-1.0)$ & $4.7(0-40.0)$ \\
\hline${ }^{*}$ cyclin E-LI (range) & $1.1(0-18.0)$ & $1.1(0-18.0)$ & $1.1(0-18.0)$ & $1.1(0-18.0)$ \\
\hline${ }^{*}$ E2F 1-LI (range) & $5.6(0-30.0)$ & $10.3(0-38.1)$ & $5.3(0-10.6)$ & $7.7(0-38.1)$ \\
\hline *MIB1-LI (range) & $13.3(4.1-40.3)$ & $10.4(1.7-33.9)$ & $11.5(6.5-16.5)$ & $11.8(1.7-40.3)$ \\
\hline
\end{tabular}

${ }^{*}$ Mean value.
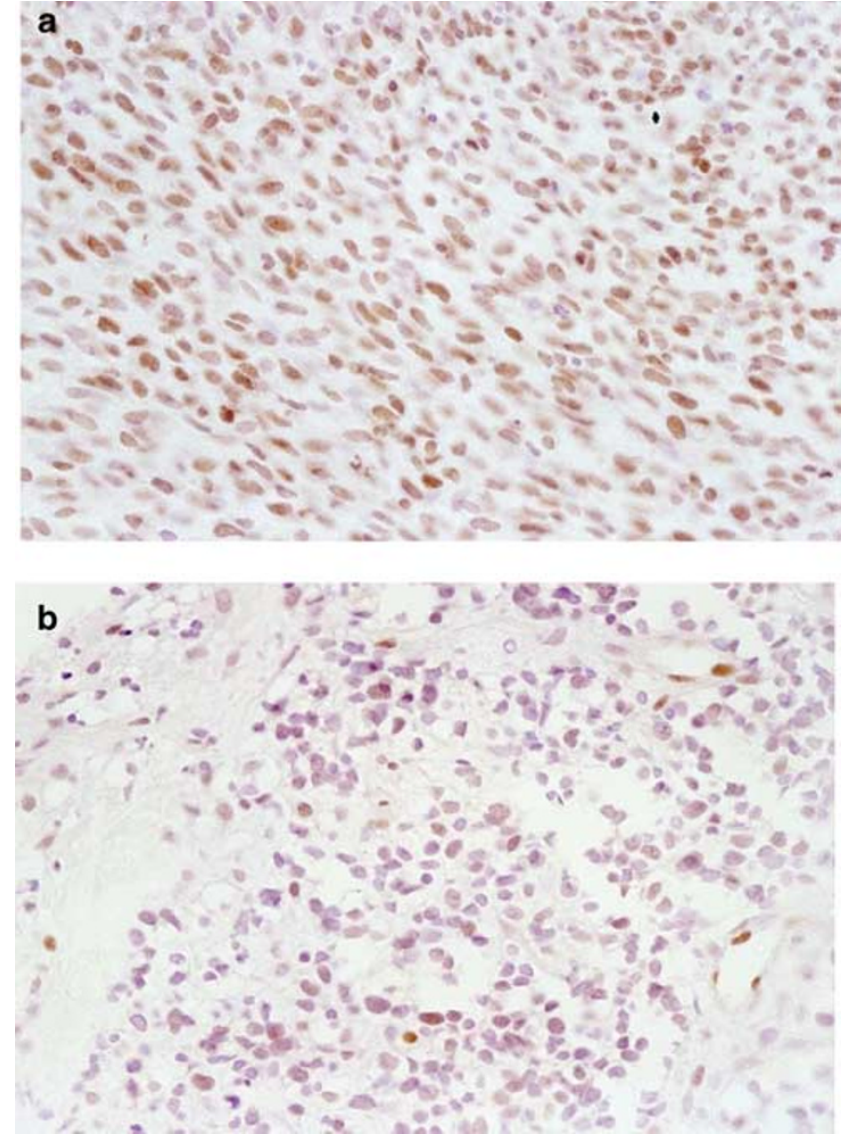

Figure 3 Immunohistochemical staining for pRB. (a) Tumor in the pelvic cavity of a 1-year-old female, embryonal type. The patient died of the disease 9 months after surgery (RMS5). A positive nuclear reaction in most tumor cells. (b) Tumor of the shoulder of a 13-year-old female, alveolar type. The patient remains alive 153 months after surgery (RMS51). Heterogeneous expression can be seen in some cells.

$(n=25,34.7 \%)$ or negative $(n=23,31.9 \%)$. The mean LI and SD for p21, p27, cyclin D1, cyclin E, MIB-1 and E2F-1 were 5.64 and 11.86 (range, 0-68.0), 5.49 and 11.22 (range, 0-64.0), 4.68 and 8.89 (range, 040.0), 2.31 and 5.11 (range, 0-28.0), 11.80 and 8.46

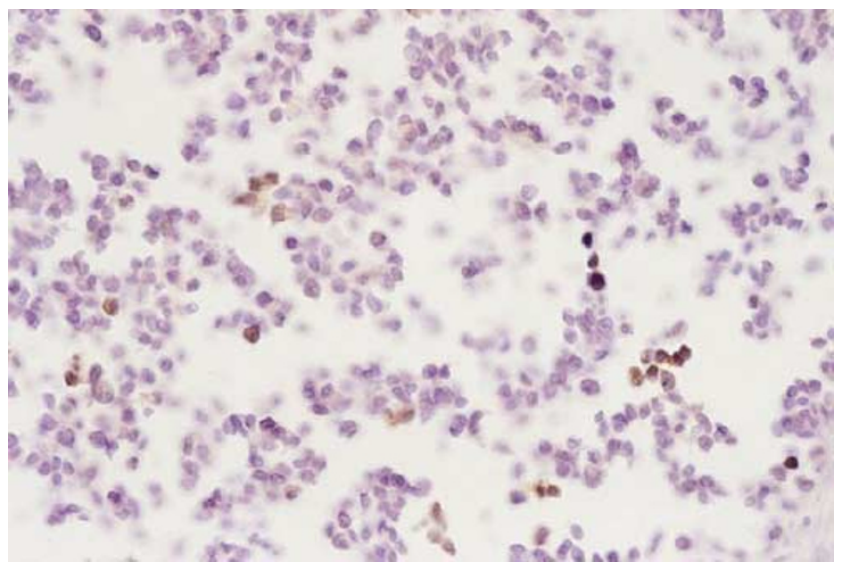

Figure 4 Immunohistochemical staining for cyclin D1 $(\mathrm{LI}=6)$. Tumor of the finger of a 17-year-old female, alveolar type. The patient died of the disease 2 months after surgery (RMS9).

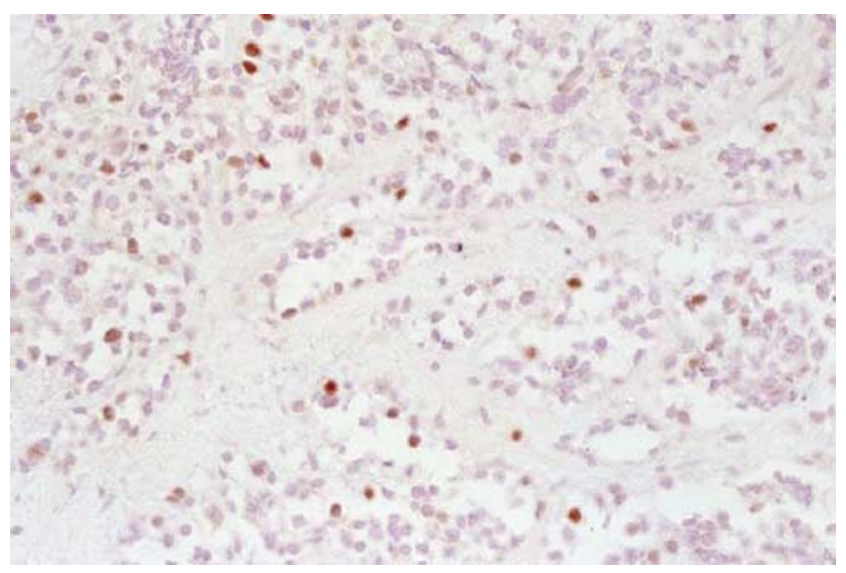

Figure 5 Immunohistochemical staining for E2F in alveolar type $(\mathrm{LI}=14)$. Orbital tumor of 25 -year-old male, alveolar type (RMS3).

(range, 1.7-40.3) and 7.65 and 9.47 (range, 0-38.1), respectively (Figures 4 and 5).

Of the 72 rhabdomyosarcoma cases analyzed, nuclear accumulation of p53 was detected in 22 cases $(30.5 \%)$ (Figure 6), while overexpression of MDM2 was found in nine cases $(12.5 \%)$. 
There were some relationships between the expressions of cell-cycle-related proteins and clinicopathological parameters. Altered $\mathrm{pRb}$ levels $(P=0.0297)$ and a high cyclin D1 LI $(P=0.048)$ were significantly correlated with those tumor sites that were related to poor prognosis. Cyclin E (embryonal type: 1.11 vs alveolar type: 3.68, $P=0.037$ ) and E2F-LI (embryonal type: 5.58 vs alveolar type: 10.33, $P=0.0334$ ) showed a high score in the alveolar type compared with that noted in the embryonal type. A statistically significant association was observed between p53 overexpres-

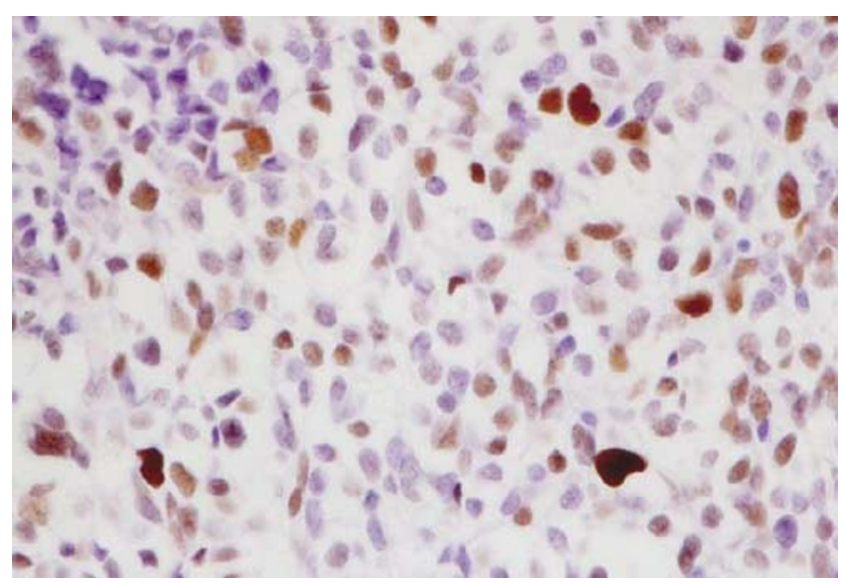

Figure 6 p53 immunoreactivity is observable in Case RMS51.

Table 4 Correlation between immunoreactivity or labeling index of cell cycle regulators and labeling index of MIB 1 and E2F 1 in rhabdomyosarcoma

\begin{tabular}{lcccc}
\hline & $\begin{array}{c}\text { MIB1-LI } \\
\text { Mean }\end{array}$ & P value & $\begin{array}{c}\text { E2F 1-LI } \\
\text { Mean }\end{array}$ & P value \\
\hline p53 & & & & \\
$-(n=49)$ & 10.5 & $0.0350^{*}$ & 7.7 & 0.4957 \\
$+(n=21)$ & 15.2 & & 8.4 & \\
MDM2 & & & & \\
$-(n=61)$ & 11 & $0.0360^{*}$ & 7.8 & 0.8384 \\
$+(n=9)$ & 18.2 & & 8.5 & \\
p16 & & & & \\
$-(n=17)$ & 13.6 & 0.3801 & 7.3 & 0.8313 \\
$+(n=53)$ & 11.4 & & 8.1 & \\
RB & & & & \\
$-(n=18)$ & 14.7 & 0.1167 & 9.4 & 0.3331 \\
$+(n=52)$ & 10.9 & & 7.4 & \\
p21LI & & & & \\
L $(n=54)$ & 11.6 & 0.5705 & 6.5 & $0.0185^{*}$ \\
H $(n=16)$ & 13 & & 12.7 & \\
p27-LI & & & & \\
L $(n=52)$ & 10.4 & $0.0094 *$ & 7.5 & 0.5173 \\
H $(n=18)$ & 16.4 & & 9.1 & \\
cyclin D1-LI & & & & \\
L $(n=52)$ & 12 & 0.9185 & 6.3 & $0.0123^{*}$ \\
H $(n=18)$ & 11.7 & & 12.6 & \\
cyclin E-LI & & & & \\
L $(n=61)$ & 11.9 & 0.988 & 6.8 & $0.0085^{*}$ \\
H ( $n=9)$ & 11.9 & & 15.5 & \\
\hline
\end{tabular}

*Statistically significant; L: low LI; H: high LI. sion and altered p16 staining $(P=0.0292)$, but no association was found with clinicopathologic parameters. A statistically significant association was also observed between MDM2 and both p21 $(P=0.0246)$ and $\mathrm{p} 27$ expression $(P=0.0070)$, and between cyclin $\mathrm{E}$ and both $\mathrm{p} 21(P=0.0246)$ and cyclin D1 expression $(P=0.0427)$.

Table 4 presents the relationships between the MIB-1 and E2F LI and the expressions of different proteins. We used the mean values as the cutoff values for each of p21, p27, cyclin D and cyclin E LI (mean, 5.6, 5.5, 4.7, 5.1, respectively). The MIB-1 LI was significantly correlated with the immunohistochemical expression of p53 $(P=0.0350)$, MDM2 $(P=0.0360)$ and high p27 LI $(P=0.0448)$, whereas the E2F-1 LI was significantly correlated with the immunohistochemical expression of high p21 LI $(P=0.0185)$, high cyclin D1 LI $(P=0.0123)$ and high cyclin E LI $(P=0.0085)$.

P53, MDM2, p21, p27, p16, pRb, cyclin D1 and cyclin $\mathrm{E}$ all showed no association with the patients' prognoses.

\section{p53 Mutations in Exons 5-9}

In all, 10 of the 45 cases $(22.2 \%)$ had p53 gene alterations detected by molecular biological analysis (Figure 7). There were 11 mutational sites, two being silent mutations (Cases 17 and 72), and nine being missense mutations (Table 5). One tumor, which was a single case showing anaplasia (Case 31), contained two mutations at codons 247 and 249 and also demonstrated nuclear accumulation of p53 protein. As for the type of base change, there were 10 sites of transition and one site of transversion. No positive correlation was observed between p53 mutation status and the patients' prognoses or any of the other clinicopathologic parameters. In all 22 of the 72 cases $(30.6 \%)$ demonstrated nuclear accumulation of p53 protein in more than $10 \%$ of the tumor cells. Among them, four cases contained five $p 53$ mutations comprising one silent mutation and four missense mutations. There was no significant correlation between p53 immunoreactivity and p53 mutation status.

\section{MDM2 Amplification}

Differential PCR for MDM2 was available in 18 cases. Three cases (16.7\%) showed MDM2 amplification. Nine out of the 72 cases $(12.5 \%)$ showed immunoreaction for MDM2. A statistically significant association was observed between immunoreaction for MDM2 and p53 overexpression $(P=0.0002)$. Eight cases showed the coexpression of both p53 and MDM2 protein, but this did not affect the prognosis of the patients. There was no correlation between MDM2 amplification and either p53 or MDM2 overexpression. In addition, MDM2 showed no association with the patients' prognoses 
or with any of the other clinicopathologic parameters, including histological type and age.

\section{H-ras Mutation Status}

Overall, $H$-ras mutations at Codon 12 or 13 were not detected in any of these rhabdomyosarcoma clinical specimens.

\section{Discussion}

Rhabdomyosarcoma is the most commonly occurring soft-tissue sarcoma in children, accounting for $5-8 \%$ of all malignancies. ${ }^{1}$ Based on histopathologic features, rhabdomyosarcomas can be categorized into the following types: embryonal including botryoid and spindle-cell subtypes, alveolar, and also pleomorphic subtype, although this type is rare. ${ }^{2}$ It has been reported that the alveolar subtype has more aggressive features
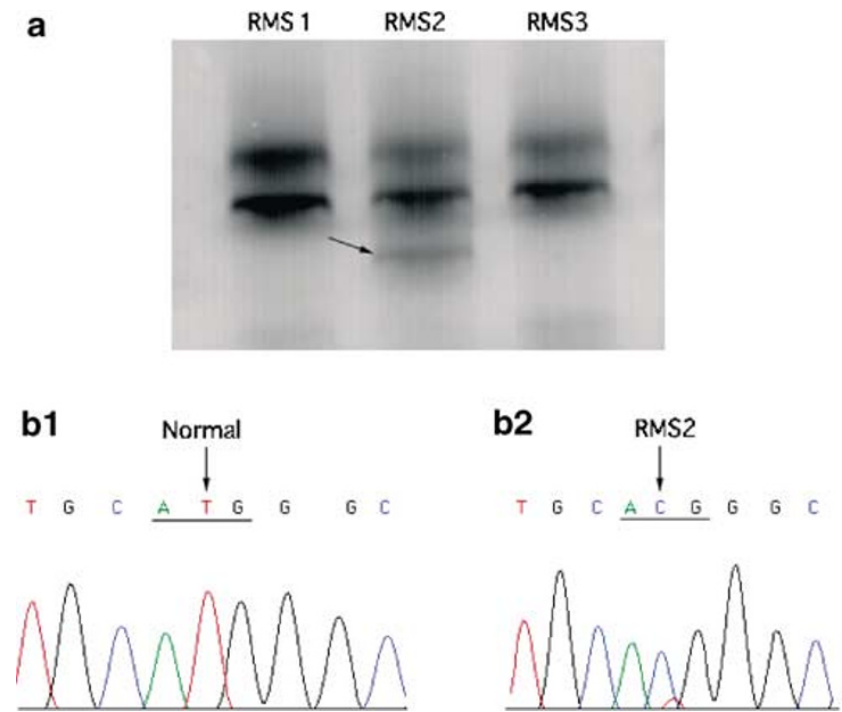

Figure 7 PCR-SSCP analysis at Exon 7. Abnormal band is evident in Case RMS2 (a). Direct DNA sequencing of Exon 7 in Case RMS2 (b). (Codon 243, ATG to ACG). than the embryonal subtype, with both the biological and clinical behavior differing among the subtypes of RMS; even within the same subtype, differences with regard to malignant behavior have been noted. It has also been reported that tumors occurring in the orbit, paratestis or head and neck show a better prognosis than those at other sites. The reasons for these findings are still unknown. In the previous reports of rhabdomyosarcoma, data concerning alteration of the cell-cycleregulatory proteins involving the p53 and the $\mathrm{Rb}$ pathways have been limited. In this study, we tried to define both the frequency of altered expression and the molecular abnormalities of cell-cycle-regulatory proteins involving the $\mathrm{p} 53 / \mathrm{Rb}$ pathway in a rather large series of rhabdomyosarcoma clinical specimens.

The expression of p53 protein in rhabdomyosarcoma has been recognized in $19-75 \%$ of cases. ${ }^{6,8,9-12}$ Ayan et al commented that the data demonstrated an apparent correlation between p53 overepression and event-free survival, but not overall survival. Lai et al also reported that p53 overexpression was related to both tumor differentiation and the degree of malignancy, and so p53 positivity may indicate a poor prognosis. In our series, of the 72 cases of rhabdomyosarcoma analyzed, nuclear accumulation of p53 was detected in 22 cases $(30.5 \%)$. In line with their report that there was no correlation between p53 overexpression and age, sex or histopathologic subtype, ${ }^{10,11}$ our data also demonstrated that p53 showed no association with the patients' prognoses or with any of the other clinicopathologic parameters. In the present study, the MIB-1 LI was significantly correlated with the immunohistochemical expression of p53 $(P=0.0350)$. No positive correlation was observed between p53 overexpression and the patients' prognoses, however, p53 overexpression was associated with a high MIB-LI, which is known as a tumor proliferation marker. Therefore, p53 overexpression would appear to be related to tumor aggressiveness in rhabdomyosarcoma.

The wild-type p53 protein is a transcriptional activator of target genes, functioning as a G1 cell-

Table 5 p53 mutations in 45 cases of rhabdomyosarcoma

\begin{tabular}{|c|c|c|c|c|c|c|c|c|c|}
\hline Case & Age/sex & Location & Histology & Exon & Codon & Base change & Amino-acid & p53 IHC & Follow-up \\
\hline RMS2 & $25 / F$ & Orbit & Alveolar & 7 & 243 & ATG-ACG & Met-Thr & + & NA \\
\hline RMS7 & $5 / F$ & Forearm & Alveolar & 8 & 291 & AAG-CAG & Cys-Gln & - & NA \\
\hline RMS17 & $2 / \mathrm{F}$ & Back & Embryonal & 7 & 240 & AGT-AGC & Ser-Ser & + & 64 mo/DOD \\
\hline RMS21 & $2 / F$ & Buttock & Embryonal & 7 & 245 & GGC-TGC & Gly-Cys & - & 61 mo/DOD \\
\hline RMS31 & $1 / \mathrm{M}$ & Cheek & Embryonal & 7 & $\begin{array}{l}247 \\
249\end{array}$ & $\begin{array}{l}\text { AAC-GAC } \\
\text { AGG-GGG }\end{array}$ & $\begin{array}{l}\text { Asn-Asp } \\
\text { Arg-Gly }\end{array}$ & + & $40 \mathrm{mo} / \mathrm{AWD}$ \\
\hline RMS39 & $16 / F$ & Forearm & Alveolar & 6 & 204 & GAG-GGG & Glu-Gly & + & 24 mo/DOD \\
\hline RMS43 & $5 / \mathrm{M}$ & Axilla & Alveolar & 8 & 295 & CCT-CAT & Pro-His & - & NA \\
\hline RMS54 & $16 / F$ & Chest wall & Pleomorphic & 6 & 209 & AGA-ACA & Arg-Thr & - & $7 \mathrm{mo} / \mathrm{DOD}$ \\
\hline RMS55 & $14 / \mathrm{M}$ & Paratestis & Embryonal & 6 & 223 & CCT-CGT & Pro-Arg & - & $319 \mathrm{mo} / \mathrm{AWD}$ \\
\hline RMS72 & $19 / F$ & Lung & Embryonal & 6 & 207 & GAT-GAC & Asp-Asp & + & NA \\
\hline
\end{tabular}

$\mathrm{mo}=$ month 
cycle checkpoint. In previous molecular studies of p53 mutation in rhabdomyosarcoma, the materials studied comprised both cell lines and clinical tumor samples, and the number of samples studied was very small, leading to results that varied greatly. In case of the materials restricted to only clinical tumor samples, the results of the previous reports of $p 53$ gene abnormalities in rhabdomyosarcoma were low, ranging from 5 to $33 \% .{ }^{4-7,13,14}$ Some investigators have reported that most patients with $p 53$ mutations were of a younger $\operatorname{age}^{7}$ and had tumors of the embryonal subtype. In the current study, 10 of the 45 cases $(22.2 \%)$ had p53 gene abnormalities detected by molecular biological analysis, including four cases of alveolar type. Although a number of mutations of p53 were detected in rhabdomyosarcoma cell lines of both embryonal and alveolar type origin, to the best of our knowledge, this is the first report of such many alveolar rhabdomyosarcoma patients with $p 53$ mutations from tumor specimens. No positive correlation was observed between p53 mutation status and the patients' prognoses or any of the other clinicopathologic parameters, including age and histological type.

MDM2 has been shown to function as a negative regulator of p53. It binds to p53 protein, thereby inactivating its transcriptional activity. ${ }^{18,19}$ In the previous limited reports, MDM2 immunoreactivity and the frequency of MDM2 gene amplification in rhabdomyosarcoma have been found to be low. Taylor et al demonstrated that of the 20 rhabdomyosarcoma cases analyzed, two cases $(10 \%)$ showed MDM2 amplification. In the report of Würl et al, positive staining was observed in $36 \%(4 / 11)$ of rhabdomyosarcoma cases and all the positive cases were Grade 3 tumor samples. Leuschner et al reported that MDM2 was expressed at low levels in pediatric rhabdomyosarcoma cases, and $10 \%$ of the cases (15/150) showed positive staining in more than $5 \%$ of the tumor cells. In addition, they did not have any cases showing both strong p53 and MDM2 expression. In our study, cases showing staining in more than $10 \%$ of the nuclei were regarded as positive cases, overexpression of MDM2 was found in nine out of 72 cases (13\%), and of the 18 rhabdomyosarcoma analyzed, three cases (16.7\%) showed MDM2 amplification. There was no correlation between MDM2 amplification and MDM2 overexpression. Xia et al showed that MDM2 amplification events occur frequently in alveolar type, but only rarely in embryonal type. ${ }^{27}$ In our study, of the three cases with MDM2 amplification, one case was alveolar type while two were embryonal type. MDM2 showed no association with the patients' prognoses or with any of the other clinicopathologic parameters, including histological type and age. Some reports have demonstrated that the coexpression of both p53 and MDM2 protein is an adverse prognostic factor in soft-tissue sarcomas. ${ }^{8,20,21}$ In our study, eight cases showed the coexpression of both p53 and MDM2 protein, but this did not affect the prognosis of the patients. The MIB-1 LI was significantly correlated with the immunohistochemical expression of MDM2 $(P=0.0360)$. A similar relationship between p53 expression and MIB-1 LI was observed, indicating that MDM2-mediated inactivation of p53 may occur in some cases. Therefore, MDM2 overexpression as well as p53 is related to tumor aggressiveness in rhabdomyosarcoma.

Several proteins that inhibit these kinase activities have been identified. All the components involved in restriction point control are targeted in oncogenesis, both the positive controllers (cyclins and CDKs) as oncoproteins as well as the negative controllers (the CKIs p16, p21 and p27) as potential tumor suppressor proteins. ${ }^{28}$ The correlation between the alterations of these proteins in rhabdomyosarcoma has not been adequately evaluated. ${ }^{22}$

Gao et $a l^{15}$ is showed that the loss of p16 protein expression in rhabdomyosarcoma was $38.3 \%$ (18/47 cases), and this was more frequently observed in alveolar type than in embryonal type. In our study, the altered expression was identified in $66.6 \%$ of cases $(48 / 72)$, that is, $76.5 \%$ of the alveolar type cases and $58.3 \%$ of the embryonal type cases. A statistically significant association was observed between p53 overexpression and altered p16 staining, but no association with clinicopathologic parameters was seen. A statistically significant association was also observed between MDM2 and both p21 and p27 expression, and between cyclin E and both p21 and cyclin D, however, each of MDM2, p21, p27, cyclin D1, cyclin E and pRb showed no association with the patients' prognoses or any of the other clinicopathologic parameters.

The $\mathrm{Rb} / \mathrm{E} 2 \mathrm{~F}$ pathway is essential in the passage of cells through the G1 phase of the cell cycle. Some studies have shown that the levels of expression of the $R b$ gene product vary in high-grade primary sarcomas and that lower levels of $\mathrm{Rb}$ protein are correlated with poor prognosis, thereby indicating that $\mathrm{Rb}$ levels may be an important prognostic variable in these tumors. ${ }^{16,29-33}$ In the present study, the tumor cells showed a variability in pRb staining, but we were unable to clarify any prognostic significance to the alterations in $\mathrm{Rb}$ protein expression found in rhabdomyosarcoma.

E2F-1 is the ultimate transcription factor along the $\mathrm{Rb} / \mathrm{E} 2 \mathrm{~F}$ pathway. E2F-1 could act as an oncogene causing uncontrolled cellular proliferation, by counteracting the negative effects of cyclin-cdk inhibitors. PRb expression was inversely correlated with MIB-1 proliferative activity in tumor cells. ${ }^{34,35}$ There was a positive correlation between the MIB-1 and E2F-1 indices, ${ }^{36-38}$ and an increase in these two proliferative indices could be interpreted as consistent with an inverse correlation with $\mathrm{pRb}$ function. There were some reports about correlation between E2F-1 and clinicopathological prognostic factors. Zhang et $a l^{36}$ reported that increased E2F-1 index correlated with the known prognostic factors of 
breast cancer, such as histological grade, stage and metastatic status. Carllotti et al $^{39}$ showed that E2F-1 LI was significantly lower in patients with choroid plexus carcinoma in children after chemotherapy than before. In the present study, E2F-1 LI showed a significantly higher score in alveolar type compared with embryonal type $(P=0.0334)$, and the alveolar type is known as one of the poor prognostic factors. As free E2F-1 mediates G1-S progression by forming complexes with other proteins, our results indicated that E2F-1 may be related to tumor progression in some cases of rhabdomyosarcoma, especially the alveolar type.

In conclusion, this is the first report of assessment of E2F-1 LI in rhabdomyosarcoma. The result is that E2F-1 LI showed a high score in the alveolar type, indicating that E2F-1 may be related to tumor progression in some cases of rhabdomyosarcoma.

\section{Acknowledgements}

This work was supported by a Grant-in-Aid for Scientific Research (C) (no. 15590304) from the Japan Society of the Promotion of Science, Tokyo, Japan. The English in this manuscript was revised by Miss K Miller (Royal English Language Centre, Fukuoka, Japan).

\section{References}

1 Raney RB, Tefft M, Hays DM, et al. Rhabdomyosarcoma and the undifferentiated sarcomas. In: Pizzo PA, Poplack DG (eds). Principles and Practice of Pediatric Oncology. JB Lippincott Company: Philadelphia, ST, 1993, p 769.

2 Parham DM, Barr FG. Embryonal rhabdomyosarcoma. In: Fletcher CDM, Unni KK, Mertens F (eds). WHO Classification of Tumours, Pathology and Genetics of Tumours of Soft Tissue and Bone. IARC Press: Lyon, France, 2002, pp 146-154.

3 Harms D. Alveolar rhabdomyosarcoma: a prognostically unfavorable rhabdomyosarcoma type and its necessary distinction from embryonal rhabdomyosarcoma. In: Soft Tissue Tumors. Springer-Verlag: Berlin, Germany, 1995, pp 273-296.

4 Kusafuka T, Fukazawa M, Oue $\mathrm{T}$, et al. Mutation analysis of p53 gene in childhood malignant solid tumors. J Pediatr Surg 1997;32:1175-1180.

5 Taylor AC, Shu L, Danks MK, et al. P53 mutation and MDM2 amplification frequency in pediatric rhabdomyosarcoma tumors and cell lines. Med Pediatr Oncol 2000;35:96-103.

6 Yoo J, Lee HK, Kang CS, et al. p53 gene mutations and p53 protein expression in human soft tissue sarcomas. Arch Pathol Lab Med 1997;121:395-399.

7 Diller L, Sexsmith E, Gottlieb A, et al. Germline p53 mutations are frequently detected in young children with rhabdomyosarcoma. J Clin Invest 1995;95:16061611.

8 Würl P, Taubert H, Bache M, et al. Frequent occurrence of p53 mutations in rhabdomyosarcoma and leiomyo- sarcoma, but not in fibrosarcoma and malignant neural tumors. Int J Cancer 1996;69:317-323.

9 Yoo J, Park SY, Kang SJ, et al. Altered expression of G1 regulatory proteins in human soft tissue sarcomas. Arch Pathol Lab Med 2002;126:567-573.

10 Ayan I, Dogan Ö, Kebudi R, et al. Immunohistochemical detection of p53 protein in rhabdomyosarcoma: association with clinicopathological features and outcome. J Pediatr Hematol Oncol 1997;19:48-53.

11 Lai R, Luo Z, An J. The correlation between expression of oncogene protein products p53, p21, p185 and cell differentiation and prognosis in rhabdomyosarcoma. Chung-Hua Ping Li Hsueh Tsa Chih-Chinese J Pathol 1997;26:35-37.

12 Leuschner I, Langhans I, Schmitz R, et al. p53 and mdm-2 expression in rhabdomyosarcoma of childhood and adolescence: clinicopathologic study by the Kiel Pediatric Tumor Registry and the German Cooperative Soft Tissue Sarcoma Study. Pediatr Dev Pathol 2003;6:128-136.

13 Stratton MR, Moss S, Warren W, et al. Mutation of the p53 gene in human soft tissue sarcomas: Association with abnormalities of the RB1 gene. Oncogene 1990;5:1297-1301.

14 Felix CA, Kappel CC, Mitsudomi T, et al. Frequency and diversity of p53 mutations in childhood rhabdomyosarcoma. Cancer Res 1992;52:2243-2247.

15 Gao Z, Zhang S, Yang G. A study of p16 gene and its protein expression in rhabdomyosarcoma. Chung-Hua Ping Li Hsueh Tsa Chih-Chinese J Pathol 1998;27:290-293.

16 Chiara AD, T'Ang A, Triche TJ. Expression of the retinoblastoma susceptibility gene in childhood rhabdomyosarcomas. J Natl Cancer Inst 1993;85:152-157.

17 Mulligan LM, Matlashewski GJ, Scrable HJ, et al. Mechanism of p53 loss in human sarcomas. Proc Natl Acad Sci 1990;87:5863-5867.

18 Momand J, Zambetti GP, Olson DC, et al. The MDM2 oncogene product forms a complex with the p53 protein and inhibits p53-mediated transactivation. Cell 1992;69:1237-1245.

19 Oliner JD, Pietenpol JA, Thiagalingam S, et al. Oncoprotein MDM2 conceals the activation domain of tumour suppressor p53. Nature 1993;362:857-860.

20 Cordon-Cardo C, Latres E, Drobnjak M, et al. Molecular abnormalities of $m d m 2$ and p53 genes in adult soft tissue sarcomas. Cancer Res 1994;54:794-799.

21 Würl P, Meye A, Schmidt H, et al. High prognostic significance of mdm2/p53 co-overexpression in soft tissue sarcomas of the extremities. Oncogene 1998;16:1183-1185.

22 Kaleti J, Quezado MM, Abaza MM, et al. The mdm oncoprotein is overexpressed in rhabdomyosarcoma cell lines and stabilizes wild-type p53 protein. Am J Pathol 1996;149:143-151.

23 Yoo J, Robinson RA. H-ras, and K-ras mutation in soft tissue sarcoma. Comparative studies of sarcomas from Korean and American patients. Cancer 1999;86:58-63.

24 Oda Y, Sakamoto A, Saito T, et al. Molecular abnormalities of p53, MDM2, and H-ras in synovial sarcoma. Mod Pathol 2000;13(9):994-1004.

25 Reid AH, Tsai MM, Venzon DJ, et al. MDM2 amplification, p53 mutation, and accumulation of the p53 gene product in malignant fibrous histiocytoma. Diagn Mol Pathol 1996;5:65-73. 
26 Kawaguchi K, Oda Y, Sakamoto A, et al. Molecular analysis of p53, MDM2, and H-ras genes in osteosarcoma and malignant fibrous histiocytoma of bone in patients older than 40 years. Mod Pathol 2002; 15(9):878-888.

27 Xia SJ, Pressey JG, Barr FG. Molecular pathogenesis of rhabdomyosarcoma. Cancer Biol Ther 2002;1(2):97-104.

28 Bartek J, Bartkova B, Staskova Z. Aberrant expression of the p53 oncoprotein is a common feature of a wide spectrum of human malignancies. Oncogene 1991;6: 1699-1703.

29 Reissmann PT, Simon MA, Lee WH, et al. Studies of the retinoblastoma gene in human sarcomas. Cancer Cells 1989;7:229-234.

30 Wunder JS, Czitrom AA, Kandel R, et al. Analysis of alterations in the retinoblastoma gene and tumor grade in bone and soft-tissue sarcomas. J Natl Cancer Inst 1991;83:194-200.

31 Cance WG, Brennan MF, Dudas ME, et al. Altered expression of the retinoblastoma gene product in human sarcomas. N Engl J Med 1990;323:1457-1462.

32 Wang J, Coltrera MD, Gown AM. Abnormalities of p53 and p110RB tumor suppressor gene expession in human soft tissue tumors: correlations with cell proliferation and tumor grade. Mod Pathol 1995; 8:837-842.

33 Cohen JA, Geradts J. Loss of RB and MTS1/CDKN2 (p16) expression in human sarcomas. Hum Pathol 1997;28:893-898.
34 Morente M, Piris M, Abraira V. Adverse clinical outcome in Hodgkin's disease is associated with loss of retinoblastoma protein expression, high Ki67 proliferation index, and absence of Epstein-Barr viruslatent membrane protein 1 expression. Blood 1997;90:2429-2436.

35 Nakamura M, Konishi N, Tsunoda S, et al. Retinoblastoma protein expression and MIB-1 correlate with survival of patients with malignant astrocytoma. Cancer 1997;80:242-249.

36 Zhang SY, Liu SC, Al-Saleem LF, et al. E2F-1: a proliferative marker of breast neoplasia. Cancer Epidemiol Biomarker Prev 2000;9:395-401.

37 Olvera M, Harris S, Amezcua CA, et al. Immunohistochemical expression of cell cycle proteins E2F-1, Cdk-2, Cyclin E, p27 ${ }^{\mathrm{kip} 1}$, and Ki-67 in normal placenta and gestational trophoblastic disease. Mod Pathol 2001;14:1036-1042.

38 Orjuela $\mathrm{M}$, Orlow SI, Dudas $\mathrm{M}$, et al. Alterations of cell cycle regulators affecting $\mathrm{RB}$ pathway in nonfamilial retinoblastoma. Hum Pathol 2001;32: 537-544.

39 Carlotti Jr CG, Salhia B, Weitzman S, et al. Evaluation of proliferative index and cell cycle protein expression in choroid plexus tumors in children. Acta Neuropathol 2002;103(1):1-10. 